\title{
History and fundamental principle of Instrument Land- ing System (ILS) and technical detailed architecture of ILS transmitter and receiver
}

\author{
Mehran khan ${ }^{1}{ }^{*}$, Faiza Ali $^{2}$, M. Nasir Bashir ${ }^{3}$ \\ ${ }^{1,3}$ National University of Sciences and Technology, Islamabad, Pakistan \\ ${ }^{2}$ Health Safety and Environment Department, Engro Power Generation, Thar, Karachi
}

\author{
Keywords \\ Instrument Landing System (ILS) \\ Glide Path (GP) \\ Localizer signal \\ Microwave landing
}

Received: 11 January 2021

Accepted: 15 March 2021

Published: 7 June 2021

\begin{abstract}
In this paper a review is made of the History, Fundamental principle, and Architecture of Instrument Landing System (ILS) RF Circuits in the Receiver and Transmitter Antenna Array. The study was motivated by a need to cater to the increasing availability and use of aerial vehicles such as drones and that the conventional landing system is insufficient and risks being overwhelmed, thus this study aims to explore alternative paths and particularly the option of the MLS as a possible cure. The paper describes the Localizer and Glide path of the System. This paper gives small introduction of Microwave Landing System (MLS) and Enhance ILS Category-I Category-II Category-III is used. An additional purpose served by this study is to layout the requirements that an MLS would require in regard to its implementation and what factors would need to be considered by any organization willing to implement the system. The argument is built up by first assessing the existing infrastructure of landing systems; their origins and effectiveness, following this, the advances system such as the MLS are introduced, their current applications and potential are discussed. A comparison is made between the two to highlight the superiority of the MLS. The study carried out in this paper finds the limitations in the ILS method as they are only capable of carrying out landing in a straight path and further limited by geography. MLS on the other hand is more versatile and is capable of carrying out multiple landing approaches across multiple curved paths for a single installation. The study examines the advantages of implementing the MLS system in Pakistan.
\end{abstract}

(C) 2021 The Author(s). Published by TAF Publishing.

\section{INTRODUCTION}

ILS is applied to deliver a signal for safe and harmless cruising of airplane during the time when visibility is low or in cloudy weather etc [1]. To lessen the danger of alteration of course, main airfields bring radio aids in use, and the typical support that is considered not visible to final landing, is ILS (instrument-landing-system) [2]. ILS appeared in the late 19th century and has been used in civil landing equivalent of Category-I [3]. The ILS is the fruit of development work complied over a span of 30 years. The work done from 1928 to 1938 was explained in the June 1938, issue of proceeding of the IRE $[4,5]$. During the arena of World War II ILS had been used for national scheme, and army started the attainment of a compact form of this technique. Butt and McFarland [6] All of the major airports in the World are equipped with this system but most of the international airports got advanced from this system. Butt and McFarland [6] ILS is a precise landing system which got approved by International Civil Aviation Organization (ICAO) for its utilization while landing in almost zero visibility i.e., category III landings [7]. The horizontal and perpendicular or vertical control are attained by localizer and glideslope radio signal transmitters, respectively. Buaon et al., [8] A localizer's array of antennas is typically placed besides one end of the runway called departure end and usually comprise of many directional antennas usually in pairs [9].

The ILS however suffers from several disadvantages such as there are only 40 channels available worldwide, the az-

\footnotetext{
*Corresponding author: Mehran khan

†email:mnasir@ceme.nust.edu.pk
} 
imuth and glideslope beams are fixed and narrow, it requires flat cleared land for operation and can not be cited in hilly terrain, buildings have to kept away from the transmission areas to avoid disturbances. All these demerits make ILS more incompatible with the growing need to manage multiple aircrafts and aerial vehicles $[10,11]$. This is particularly apt in the case for unmanned vehicles where the absence of the pilot adds a layer of technicalities that are the subject of study by the aviation community. This paper is aimed at introducing the mechanisms that can compensate for these new dilemmas particularly in Pakistan.

A study carried out by Li et al., [12] discussed the role of multiple landing systems for the design of large civil aircraft landing system. The methods were evaluated against cost, comfort and safety and performances were simulated. This allowed for a creation of a framework to assess landing systems and their effectiveness.

Another study by Klochan et al., [13] dealt with the question of developing landing systems for UAVs that would allow for the determination of flight and navigation parameters during landing. The paper proposed a polarimetric landing system for UAVs, which relies on the same basic principles as the MLS.

Shirokova et al carried out a study in which precision positioning of a UAV during landing is discussed [14]. They propose a solution by utilizing a microwave phase radio for object positioning. The main advantages of the system as proposed in this study is that it is inexpensive and lightweight. As demonstrated much research has been carried out to improve the landing systems currently in use. This study aims to enhance the readers understanding of current and proposed systems and to further exemplify the advantages of the proposed systems.

\section{METHODOLOGY}

Firstly, Basic principle of ILS has been studied with each of its components (localizer, glide slope) and, architecture of ILS transmitter and receiver. Secondly, other Landing Systems are reviewed to enhance readers understanding of landing systems.

\section{A. Basic Principle of Ils}

Horizontal gaudiness is provided by Localizer which produce a radio beam along with a landing track which is actually an enlargement of runway-centreline, the domain of localizer signal is at least 20NM [15]. The Localizer usually transmit in the very high frequency navigation band (VHF) lying within the range of 108.1 and $111.95 \mathrm{MHz}$ using each odd number of $100 \mathrm{KHz}$ and each odd number of $100 \mathrm{KHz}$
+ $50 \mathrm{KHz}$ the frequencies are; 108.10108 .15108 .30108 .35 111.90 and $111.95 \mathrm{MHz}$ which actually forms an integral of 40 frequency, out of which 38 frequencies are utilized for the purpose of navigation and 2 for experimental reasons. 2 frequencies are 108.1 MHz and 108.15MHz [16]. Vertical or perpendicular lead is provided by the glide slope spreader which work like the localizer. It provides with the singular approach path like localizer, which is nominally a 3 down maneuver read from parallel or horizontal. According to ICAO standards ILS must include [17].

\section{B. Localizer}

The purpose of localizer is to provide the adjustment or lateral course guidance to land an aircraft on an ILS runway [18]. Two signals are supposed to be transmitted on 1 out of 40 ILS channels among the carrier frequency ranges which we discuss in the introduction. One is regulated by $90 \mathrm{~Hz}$, and other is regulated by $150 \mathrm{~Hz}$ which are broadcasted from different but located at same areas antennas. A converged coherent beam is transmitted by each antenna, one is on left side of the runway centreline, and the next one is located on right side [9]. As shown in Figure 1.
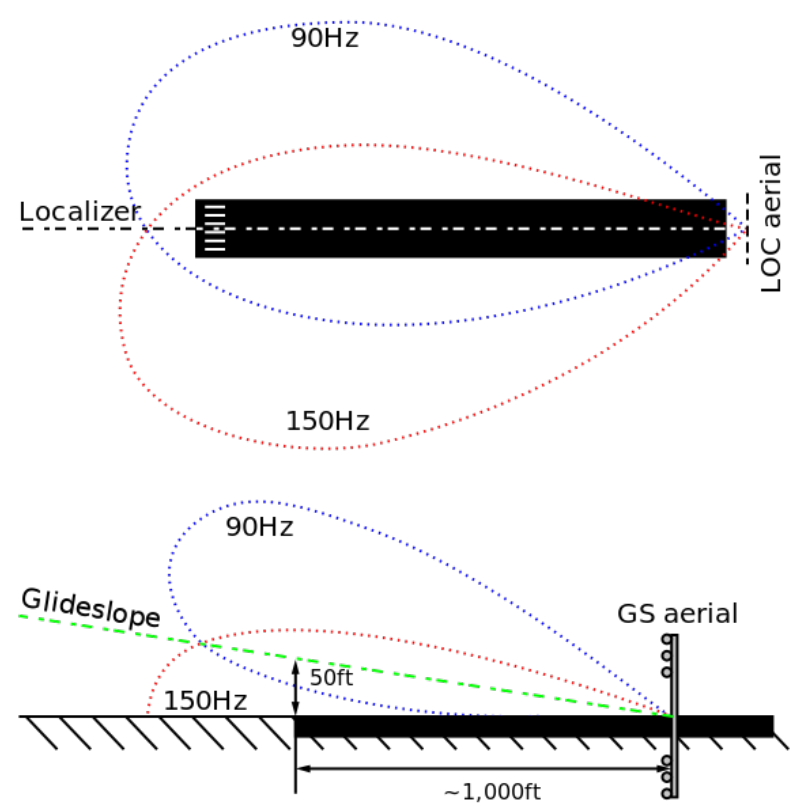

Fig. 1. Emission patterns of the localizer and glide slope signal [15]

\section{Glide Slope}

As we discuss above instrument-landing-system provides an alert to the pilot corresponding to azimuthal and elevation data for smooth and safe descent. Glide slope schemes provides us with the information about elevation or perpendicular data [19]. The glide slope enables us with vertical guidance that is almost identical to the localizer. The 
glide-path generator (elevation transmitter) generates two converged rays in elevation plane as shown in Figure 1, the glide path in this case is equally distant [20]. Commonly two types of glide slope schemes are in general, non-image and image. Requirement of image glide slope path is the reflecting surface or ground as a reflecting plane, whereas, in case of non-image glide slope no legit reflection plane is compulsory $[2,21]$. Image type scheme are basically general most, kinds of instrument-landing-glide-slope scheme [22]. These schemes make a track in atmosphere that can actually be used by an appropriately instrumented or equipped aircraft for a safe descent or landing under unfavourable climate states. Interference occurring between the absolute straight rays and the scattering back from ground, from ordinary dipole or doublet antennas form this track [23]. For standard elevation approach supervision, in 1950 ICAO acquired the 330-MegaHertz null-reference glide path known as the ILS [24]. To decrease the necessity of the ground an effort has been done to utilize elements emitting radiations which were plain boarded in the runway [25]. Other approaches by bringing in use an antenna with a huge or large aperture, an inflated phase centre tried to decrease entire field radiated towards the ground surface $[26,25]$. A cockpit display is driven by the glide slope receiver which tells the necessary information to the pilot about how much below or above the track is the airplane situates. The objective of the pilot's is to glide the airplane in order to keep Course Deviation Indicator (CDI) needle always at centre. In case of its fulfilment and if all systems are operating smoothly, the pilot would soar without any danger to a mark above and close to landing strip, at that time the pilot can choose either he performs his landing. It is demonstrated in Figure 2 [27].

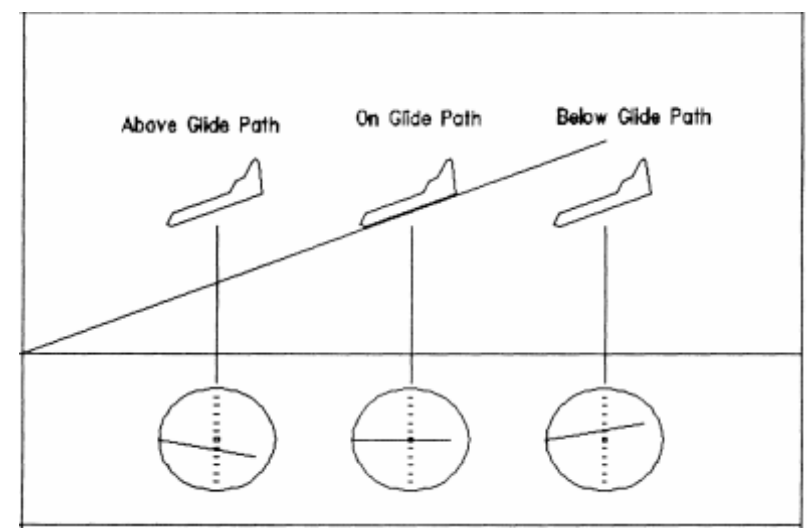

Fig. 2. Glide slope position of aircraft relative to CDI (Course Deviation Indicator) [28]

\section{Marker Beacon}

Marker beacon provide pilot alert along the approach path. A fan shaped vertical ray is radiated by each beacon which is approximately \pm 40 wide ahead the glide path by \pm 85 wide at right angle to the path (half power point) [28]. Middle Marker (MM) is situated near the mark where missed-approach decision will require to be constructed for category-I approach procedure (nominally 3000 feet from threshold). The middle marker is modulated one $1300 \mathrm{~Hz}$ dash-dot pair each second. The inner marker (IM) maybe required at runway certified from category-II and III [29]. Outer marker is placed about 3.9NM (nautical miles) distance to the runway threshold, its adjustment is done over the front ray of localiser. Its objective is to grant distance, vertical limit and equipment operating dos and don'ts to aircraft on final access. It is modulated at $400 \mathrm{~Hz}$.and keyed to send dashes continuously [30].

\section{E. Reciver and Transmitter Antenna Array}

1) Localizer antenna array: The standard localizer is an array of antennas which is situated at 600 to $1000 \mathrm{ft}$. beyond stop end of runway. Generally, Log Periodic Dipole antennas (LPD) are used which has gain of about $14 \mathrm{~dB}$ [31].

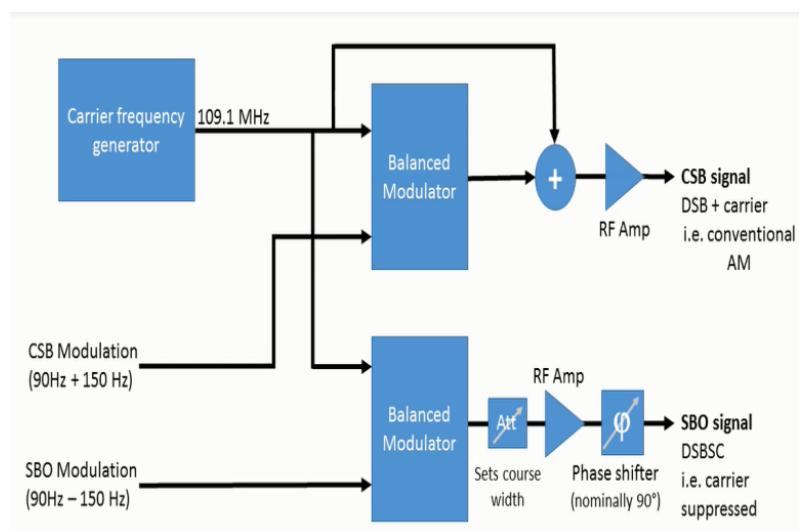

Fig. 3. Method of generating Localizer signal [29]

The Localizer station consist of two transmitters,for course and cleareance.they operate on two frequencies and each provide two output, CSB and SBO an antenna changeover unit selects one of two transmitters for the localizer [32]. 


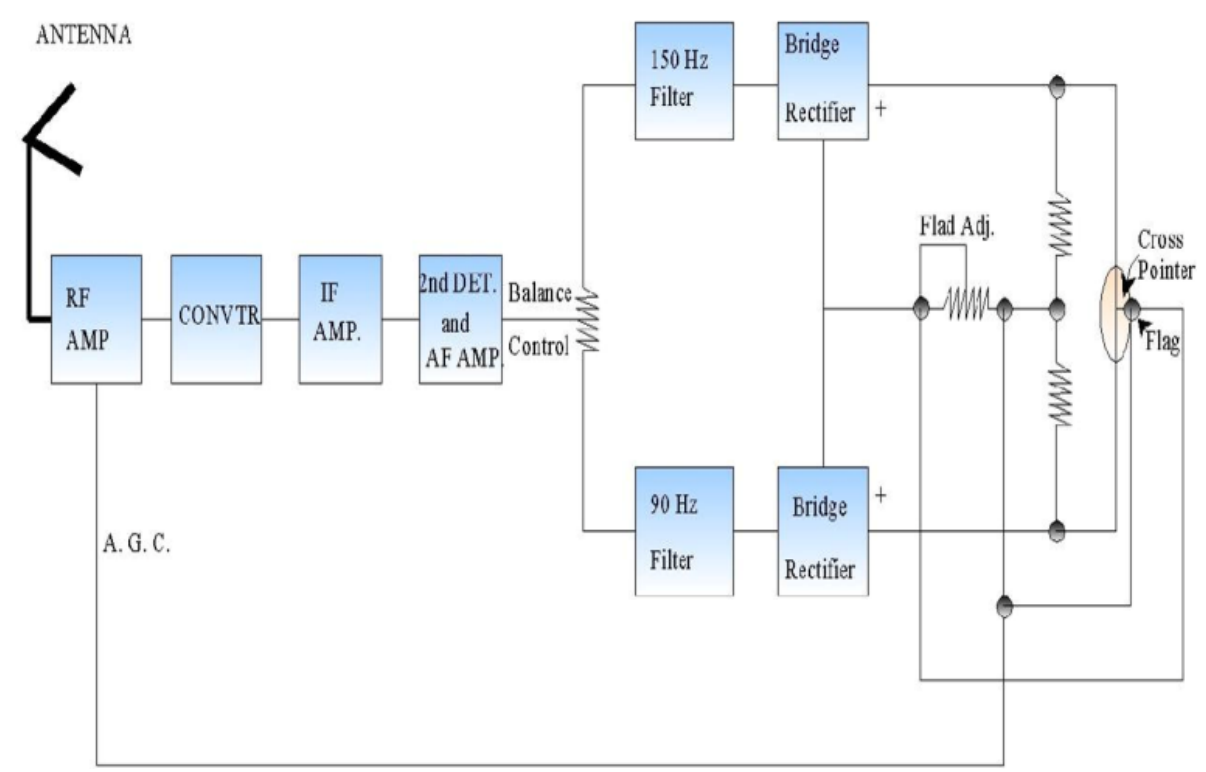

Fig. 4. Schematic illustration of typical localizer receiver [33]

In an ordinary heterodyne Amplitude Modulation (AM) Receiver, the obtained localizer signal is processed like the schematic illustration shown in Figure 4 contains the rays emitted from the undesired and desired localizer. Since the two, undesired and desired localizer lay inside the similar frequency ranges, the signals will be processed by the receiver [34].

\section{RESULST AND DISCUSSION}

\section{A. Glide Slope Antenna Array}

A frequency of $328 \mathrm{MHz}$ to $336 \mathrm{MHz}$ is operated on by glide slope antennas on a minimal impedance of $50 \Omega$ and powers up to 50W. Two transmitter fed null reference glide slope antenna schemes, one located on the high frequency or carrier frequency and second one on sideband frequency. A Glide slope antenna Array shown in Figure 5 [35].

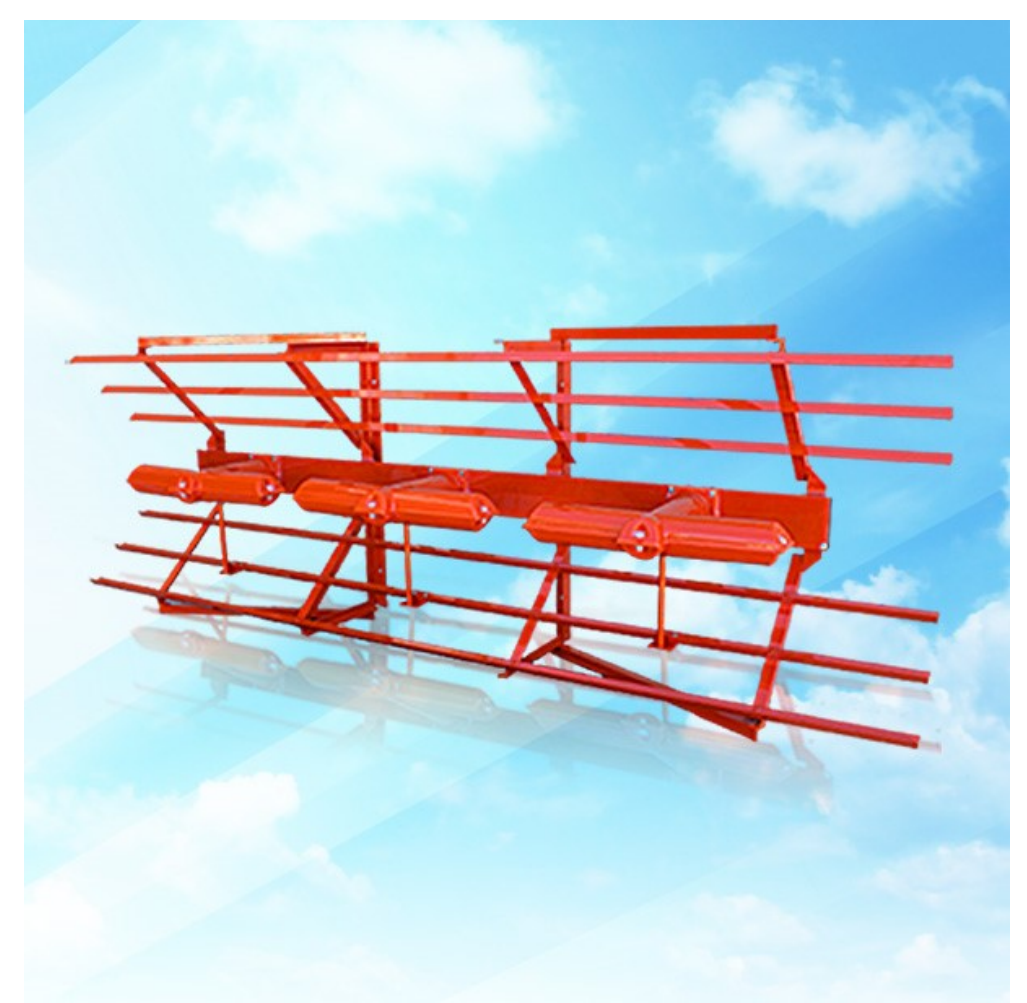

Fig. 5. Instrument landing Glide Slope Antenna (ILS-420 Certified 328-336 $\mathrm{MHz}$ [36] 
Receiver circuit of Marker beacon shown in Figure 6 the $75 \mathrm{MHz}$ marker is modulated by 3 audio tones. The outer marker is AM with $400 \mathrm{~Hz}$ and identified with two dashes per second. The MM is modulated by $1300 \mathrm{~Hz}$ tone, with alternating dashes and dots. IM is modulated by a $3 \mathrm{KHz}$ tone, by 6 dots per second.

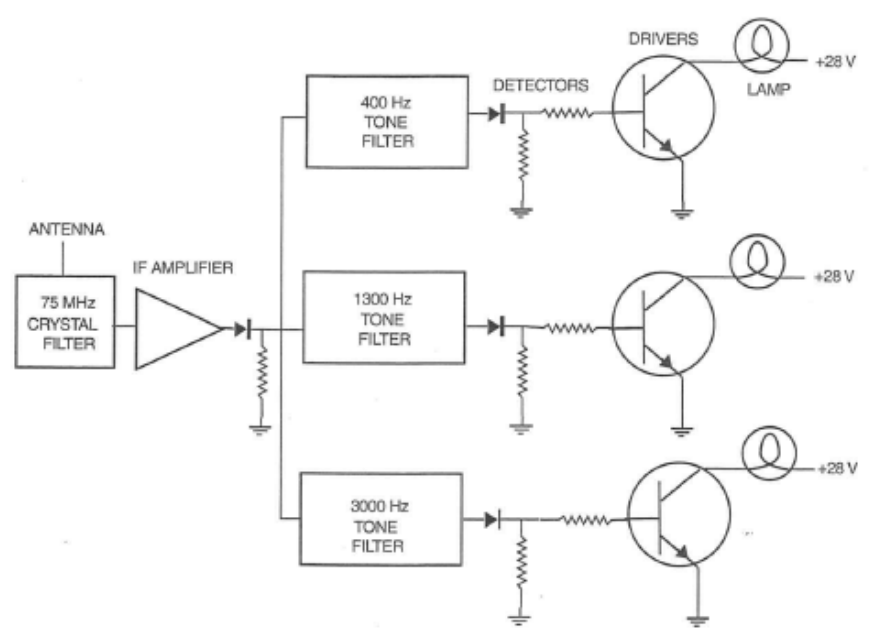

Fig. 6. TRF marker beacon receiver [3]

\section{B. MLS}

In 1983 the International Civil Aviation Organization (ICAO) introduced precision or accuracy level or approach and landing technique or system, i.e., the Time-ReferenceScanning-Beam (TRSB) based MLS, in order to cater with the disadvantages of conventional ILS (instrument landing system), such as having a fixture with the glide path-angle and non-resistant towards interruption [37]. From 2000 onwards, China had implemented MLS for approach landing. Comparatively, MLS guidance signals perform way in better range covered, better and precise functioning and admittance to approach [38]. MLS consist of ground and flying equipment. Airborne equipment receives and performs necessary procedures regarding signals in air and compute axis of runway [39]. FAA is developing a scanning beam MLS that is targeted to swap the general ILS. One feature of MLS is the ability to decrease multipath error by the usage of antennas comprising narrow-beam [40].

The approach AZ (azimuth) antenna is situated at the terminating or stop end, as is ILS localizer, and scan beam to \pm 60 degree in $\mathrm{AZ}$ (azimuth) to all sides of runway centre line as shown in Figure 7 many sites in United states would scan \pm 40 degrees. Elevation antenna is situated at approximately 1,000 feet. ILS glideslope antenna has a scan coverage from 0.9 degree to 30 degrees from the runway threshold at the Glide Path Intercept Point (GPIP), as shown in Figure 8, but many sites would scan to about 20 degrees [41].

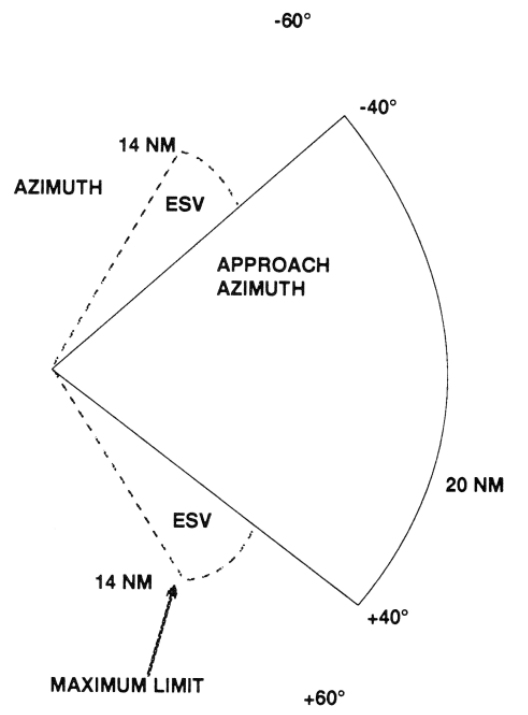

Fig. 7. Azimuth antenna coverage

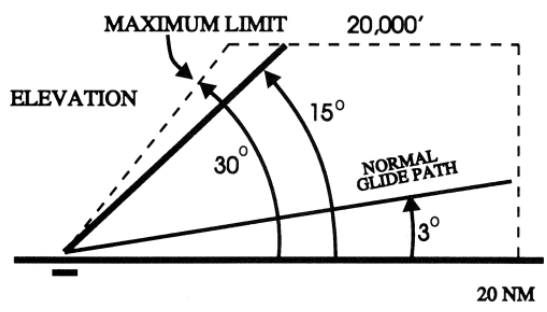

Fig. 8. Elevation antenna coverage 


\section{Enhance Landing System}

Enhanced model proposes replacing sender location from airport to the airplane, and putting receiver on ground. Installed with 3 reflectors on runway, one is on centre line, one is on left and other is on the right side [42]. The sender in airplane transmits signals towards the runway, and it is then interpreted by the reflector located on the ground, as reflectors are channelled with the CPU, they enhance critical information such as heading or exact position etc., and scatters back the signal for further interpretation and it is utilized by aircraft's FMS [9].

Approaching signals are obtained in varying time orders, it is standard for airplane's FMS to realize, the movement astray from the runway's centreline [43].

\section{CONCLUSION AND IMPLICATIONS}

In this paper it is concluded that the ILS has some limitations because installation of the ILS is very expensive. Localizer system is very susceptible to interferences in the broadcasting area like large buildings, as compared to MLS. They are only capable of a single, straight line approach, for each installation, (typically requiring 7-10nm). Geography can limit the available options. MLS can do multiple curved approaches for a single installation. The MLS is of precise approach for horizontal descent or simply landing and creates a kind of an alternative to ILS system.

\section{A. Implications}

- ILS installation can be expensive because of the complication of the antenna scheme and positioning criteria.

- To prevent harmful reflections which will affect the radiated signal, ILS sensitive area and ILS critical areas constructed. Aircraft can be refrained from utilizing certain runways by positioning these critical and sensitive areas. This can conclusively delay take offs of aircraft due to enlarged hold times and enlarged spacing between aircraft.

- Localizer schemes detect interferences quite efficiently in the signal transmission area such as hilly area and large buildings.

- If landscape is irregular, reflections can give rise to an irregular glide path causing undesirable needle deflections $[29,40]$.

\section{REFERENCES}

[1] G. Chin, L. Jordan, D. Kahn, and S. Morin, "Instrument landing system performance prediction," in IEEE-MTT-S International Microwave Symposium, Palo Alto, CA, 1975.

[2] J. Supper and D. Gallagher, "Alignment and testing of instrument landing systems," Proceedings of the IEE-Part B: Electronic and Communication Engineering, vol. 109, no. 48, pp. 447-455, 1962. doi: https://doi.org/10.1049/pi-b-2.1962. 0234

[3] A. Helfrick, Principles of Avionics. New York, NY: Avionics Communications, 2010.

[4] W. Jackson, "Improvements on the instrument landing system," IRE Transactions on Aeronautical and Navigational Electronics, no. 2, pp. 85-94, 1959. doi: https://doi.org/10.1109/TANE3.1959.4201674

[5] C.-H. Chen, Y.-S. Ye, W.-T. Hsu et al., "Automatic venipuncture insertion point recognition based on machine vision," Journal of Advances in Technology and Engineering Research, vol. 4, no. 5, pp. 186-190, 2018. doi: https://doi.org/10. 20474/jater-4.5.1

[6] H. H. Butts and R. H. McFarland, "New developments in instrument landing system," IEEE Transactions on Aerospace and Electronic Systems, no. 6, pp. 477-486, 1966. doi: https://doi.org/10.1109/TAES.1966.4502044

[7] E. C. LaBerge and D. Zeng, "An analysis of the effects of RFID tags on narrowband instrument landing systems," in 26th Digital Avionics Systems Conference, Dallas, TX, 2007. doi: https://doi.org/10.1109/DASC.2007.4391863

[8] P. Buaon, N. Montree, and K. Horapong, “A software defined radio receiver for ILS localizer signal-in-space parameters inspection using Chirp-Z transform and self-adaptive AGC," in 23rd Asia-Pacific Conference on Communications (APCC), Perth, WA, 2017.

[9] P. Noshiravani and A. Rezaee, "Instrument landing system: Enhanced model," in International Conference on Signal Acquisition and Processing, Bangalore, India, 2010.

[10] F. Tomasello and D. Haddon, "Detect and avoid for unmanned aircraft systems in the total system approach," in 2011 Tyrrhenian International Workshop on Digital Communications-Enhanced Surveillance of Aircraft and Vehicles, Capri, Italy, 2011.

[11] M. A. Rawajbeh, I. A. Haddid, and H. Al-Zoubi, "Adoption of cloud computing in higher education sector: An overview," International Journal of Technology and Engineering Studies, vol. 5, no. 1, pp. 23-29, 2019. doi: https://dx.doi.org/10. 20469/ijtes.5.10004-1 
[12] C. Li and G. Hong, "Simulation and evaluation of civil aircraft auto-landing with various guidance systems," in 9th International Conference on Mechanical and Aerospace Engineering (ICMAE), Budapest, Hungary, 2018.

[13] A. Klochan, A. Al-Ammouri, M. Dekhtyar, and N. Poleva, "Fundamentals of the polarimetric UAV landing system," in 5th International Conference Actual Problems of Unmanned Aerial Vehicles Developments (APUAVD), Kiev, Ukraine, 2019.

[14] E. I. Shirokova, A. A. Azarov, N. G. Wilson, and I. B. Shirokov, "Precision positioning of unmanned aerial vehicle at automatic landing," in IEEE Conference of Russian Young Researchers in Electrical and Electronic Engineering (EIConRus), Saint Petersburg and Moscow, Russia, 2019.

[15] M. Kayton and W. R. Fried, Avionics Navigation Systems. New York, NY: John Wiley \& Sons, 1997.

[16] I. of Radio Engineers. Professional Group on Aeronautical and N. Electronics, IRE Transactions on Aeronautical and Navigational Electronics. California, CA: Sage Publications, 1960, vol. 7.

[17] V. Complement, "Visual glide slope indicator system installed at la guardia airport," Electrical Engineering, vol. 80, no. 8, pp. 456-478, 1961. doi: https://doi.org/10.1109/EE.1961.6433403

[18] G. D. Friedlander, "At the crossroads in air-traffic control ii. the view from the ground-instrument-landing systems, automated ground control, en route automation, introduction to collision-avoidance systems, positive-control airspace, improved communications, stolports, and terminal navigational aids," IEEE Spectrum, vol. 7, no. 7, pp. 69-83, 1970. doi: https://doi.org/10.1109/MSPEC.1970.5213472

[19] Sky Brary, "Instrument Landing System (ILS)," 2020. [Online]. Available: https://bit.ly/3AsgGpZ

[20] V. Ungvichian, "Design technique to reduce effects of tidal variations on an ILS glide slope system," Electronics Letters, vol. 22, no. 9, pp. 478-479, 1986.

[21] E. H. Rhoderick and E. Rhoderick, Metal-Semiconductor Contacts. Oxford, UK: Clarendon Press, 1978.

[22] W. Gracey, J. W. Jewel Jr, and G. T. Carpenter, "Measurement of the errors of service altimeter installations during landing-approach and take-off operations," 1960. [Online]. Available: https://go.nasa.gov/2XE7xw8

[23] R. Luebbers and L. Mitchell, "Tidal effects on ils glide slope," in Antennas and Propagation Society International Symposium, Stanford, CA, 1977.

[24] R. Luebbers, V. Ungvichian, and L. Mitchell, “Gtd terrain reflection model applied to ILS glide scope," IEEE Transactions on Aerospace and Electronic Systems, no. 1, pp. 11-20, 1982. doi: https://doi.org/10.1109/TAES.1982.309201

[25] J. Lucas and A. Young, "The ils glidepath: New designs for severe sites," IEEE Transactions on Aerospace and Electronic Systems, no. 6, pp. 873-883, 1978. doi: https://doi.org/10.1109/TAES.1978.308551

[26] J. Baechle and R. McFarland, "A flush-mounted runway antenna for use with the FAA Directional glide-path system," IRE Transactions on Aeronautical and Navigational Electronics, no. 2, pp. 32-39, 1960. doi: https://doi.org/10.1109/ TANE3.1960.4201729

[27] J. Lucas, "Microwave model of an instrument-landing-system glidepath," in Proceedings of the Institution of Electrical Engineers, California, CA, 1972.

[28] F. Marcum, "Design of an image radiation monitor for ILS glide slope," IEEE Transactions on Aerospace and Electronic Systems, vol. 34, no. 3, pp. 836-843, 1998. doi: https://doi.org/10.1109/7.705891

[29] A. Chopra, "Instrument Landing System (ILS)," 2018. [Online]. Available: https://bit.ly/3hSr8jq

[30] J. C. Kao and W.-P. Sung, Civil, Architecture and Environmental Engineering. Taipei, Taiwan: CRC Press, 2017.

[31] Civil Safety Aviation Authority Australia, "Corporate plan 2017-2018," 2018. [Online]. Available: https://bit.ly/ 3Ayqw9I

[32] Federal Aviation Administration, "Electronic installation and instrument for Instrument Landing System (ILS) facilities," 1993. [Online]. Available: https://bit.ly/3EI19oo

[33] Y. H. Zhang, "Instrument landing system error analysis and simulation of calibration flight," in Applied Mechanics and Materials. London, UK: Trans Tech Publ, 2013.

[34] Engineering, "Minimum operational performance standards for airborne ils localizer receiving equipment operating within the radio frequency range of 108-112 mhz," 2017. [Online]. Available: https://bit.ly/3hQUfn9

[35] D. Quinet and S. Odunaiya, "Localizer receiver proximity and capture," in 26th Digital Avionics Systems Conference, Dallas, TX, 2007.

[36] S. Odunaiya and D. Quinet, "Calculations and analysis of signal processing by various navigation receivers architectures," in The 23rd Digital Avionics Systems Conference, Salt Lake City, UT, 2004. 
[37] R. Geise, O. Kerfin, B. Neubauer, G. Zimmer, and A. Enders, "EMC analysis including receiver characteristics-pantograph arcing and the instrument landing system," in IEEE International Symposium on Electromagnetic Compatibility (EMC), Dresden, Germany, 2015.

[38] L. Qiongwei, Y. Suya, X. Fei, and M. Wenjing, "'Research on metrology for microwave landing system simulator," in IEEE 11th International Conference on Electronic Measurement \& Instruments, Harbin, China, 2013.

[39] R. Cassell, "The effects of rain on microwave landing system antenna radomes," in Symposium on Antenna Technology and Applied Electromagnetics, Winnipeg, MB, 1990.

[40] R. Geise, A. Enders, H. Vahle, and H. Spieker, "Scaled measurements of instrument-landing-system disturbances due to large taxiing aircraft," IEEE Transactions on Electromagnetic Compatibility, vol. 50, no. 3, pp. 485-490, 2008. doi: https://doi.org/10.1109/TEMC.2008.926865

[41] H. Wheeler and A. Lopez, "Multipath effects in doppler mls," Multipath Section of Hazeltine, vol. 10, no. 55, pp. 567-587, 1972.

[42] T. E. Evans, "Microwave landing system," IEEE Aerospace and Electronic Systems Magazine, vol. 1, no. 5, pp. 6-9, 1986. doi: https://doi.org/10.1109/MAES.1986.5005109

[43] J. W. Wasson, Avionic Systems: Operation \& Maintenance. Tokyo, Japan: Jeppesen Sanderson, Incorporated, 1994. 